\title{
WATER PURITY DEVELOPMENT FOR THE COUPLED CAVITY LINAC (CCL) AND DRIFT TUBE LINAC (DTL) STRUCTURES OF THE SPALLATION NEUTRON SOURCE (SNS) LINAC
}

\author{
D. Katonak, J. Bernardin, and S. Hopkins, \\ Los Alamos National Laboratory, Los Alamos, NM, 87545, USA
}

\begin{abstract}
The Spallation Neutron Source (SNS) is a facility being designed for scientific and industrial research and development. SNS will generate and use neutrons as a diagnostic tool for medical purposes, material science, etc. The neutrons will be produced by bombarding a heavy metal target with a high-energy beam of protons, generated and accelerated with a linear particle accelerator, or linac. The low energy end of the linac consists of two room temperature copper structures, the drift tube linac (DTL), and the coupled cavity linac (CCL). Both of these accelerating structures use large amounts of electrical energy to accelerate the proton beam. Approximately $60-80 \%$ of the electrical energy is dissipated in the copper structure and must be removed. This is done using specifically designed water cooling passages within the linac's copper structure. Cooling water is supplied to these cooling passages by specially designed resonance control and water cooling systems.

One of the primary components in the DTL and CCL water cooling systems, is a water purification system that is responsible for minimizing erosion, corrosion, scaling, biological growth, and hardware activation. The water purification system consists of filters, ion exchange resins, carbon beds, an oxygen scavenger, a UV source, and diagnostic instrumentation. This paper reviews related issues associated with water purification and describes the mechanical design of the SNS Linac water purification system.
\end{abstract}

\section{INTRODUCTION}

The Spallation Neutron Source (SNS) is a facility being designed for scientific and industrial research and development. SNS will generate and use neutrons as a diagnostic tool for medical purposes, material science, etc. The neutrons will be produced by bombarding a heavy metal target with a high-energy beam of protons, generated and accelerated with a linear particle accelerator, or linac. The low energy end of the linac consists of a room temperature copper structure that dissipates $60-80 \%$ of the electrical energy in the form of heat. To properly operate the linac, this waste heat must be removed. This is done using specifically designed water cooling passages within the copper linac.

The low energy portions of the linac, the Drift Tube Linac (DTL) and the Coupled Cavity Linac (CCL), accelerate protons to an energy of $185 \mathrm{MeV}$. The DTL is comprised of 6 large tanks, which each house a variety of accelerating components that require water cooling. The CCL is comprised of 4 modules, each of which contains 12 segments of 8 accelerator cavities each (total of 96 cavities per module). Schematics of a DTL tank and half of a CCL module are shown in Figure 1.

The operation of these accelerator structures requires precise temperature regulation to control thermal induced stresses and maintain the shape and resonance of the acceleration cavities. A resonance control water cooling system has been developed which will efficiently and accurately remove the waste heat from both the DTL and CCL Radio Frequency (RF) structures and provide active resonance control of the RF structures by manipulating the DTL and CCL copper dimensions through temperature control. A closed-loop modular water cooling system, shown in Figure 2, will be used to cool a single DTL tank or CCL module.

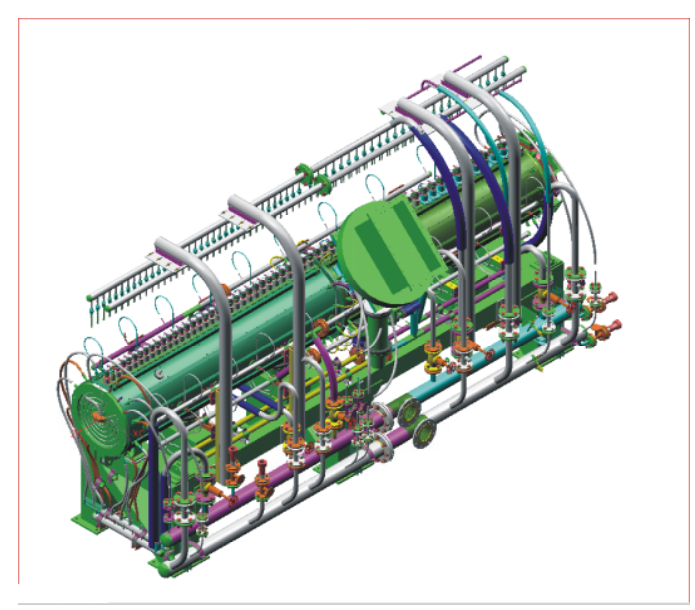

(a)

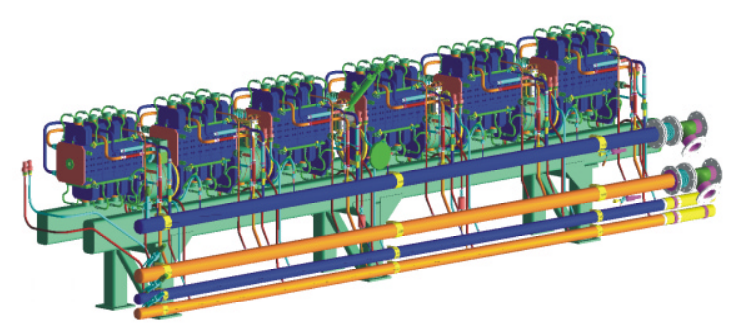

(b)

Figure 1. (a) DTL tank and (b) CCL half module. 


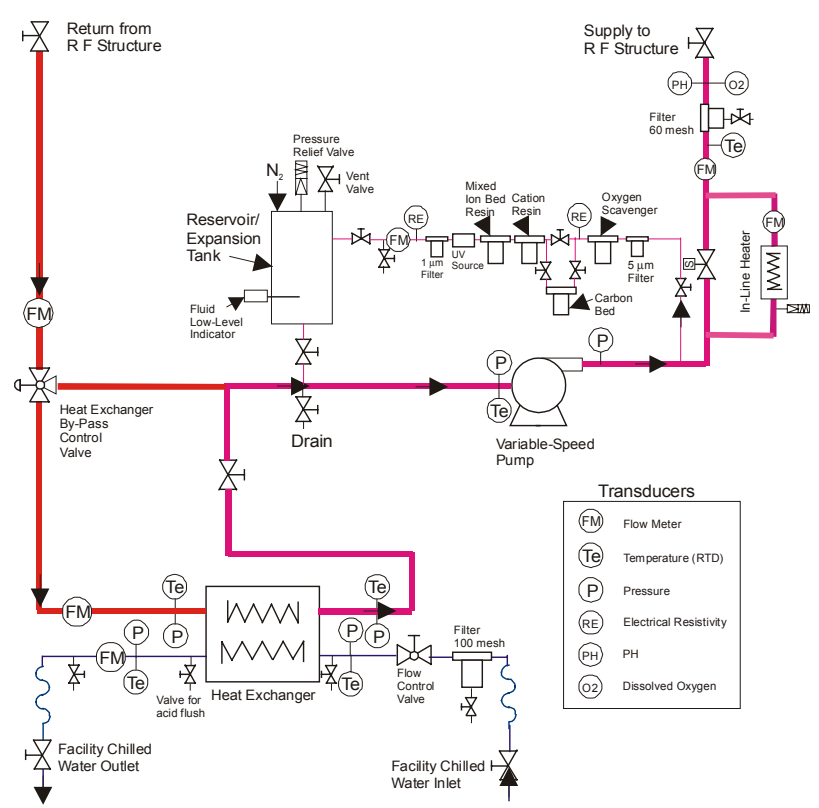

Figure 2. Flow diagram of the DTL and CCL water cooling systems.

There are several design and operational concerns in using water to cool a particle accelerator structure. Foremost among these concerns is the purity of the cooling water. The cooling water must be maintained at a high purity level to minimize the effects of erosion, corrosion, scale deposits, biological growth, and activation, all of which can significantly degrade the performance of the water cooling system and the linac.

Corrosion must be limited in the linac water cooling system to maintain cooling efficiency and minimize damage to accelerator components. Corrosion is the dissolution of a solid in a fluid (in this case, metal in water). Corrosion in the cooling passages promotes material build-up, thus reducing the heat transfer rate, increasing pressure losses, and inducing pitting and leaking. One form of corrosion, oxidation, occurs when dissolved oxygen in the water reacts with metal flowpassage walls. Galvanic corrosion occurs when two or more dissimilar metals come in contact. Minimizing dissolved oxygen and dissolved salts in the water, employing compatible building materials, and providing a galvanic insulation between dissimilar metals can significantly reduce the amount of corrosion.

Scaling is the formation of deposits, including calcium and silica salts, on metal surfaces. As the cooling water experiences a significant change in temperature, such as in a heat exchanger, the solubility of minerals and salts can decrease considerably. This change in solubility can cause minerals and salts to precipitate out of solution and eventually build up on exposed metal surfaces.

A water system is an ideal place for microorganisms to grow and reproduce. If large amounts of microorganisms are present in a water system, problems such as increased corrosion, water leaks, head loss, and a reduction in heat transfer are likely. Biological growth can be nearly eliminated by reducing the dissolved oxygen content in the water to a level, at which microorganisms cannot survive, or by passing the water through an ultraviolet light source [1]. In addition, piping must be designed to eliminate stagnation areas, or deadlegs, which are areas that have little or no flow, which can serve as a breeding ground for bacteria and a trap for dissolved oxygen. Carbon based populations can be measured by taking water samples, and are counted as Total Organic Carbon (TOC) represented as $\mathrm{mg} / \mathrm{L}$ and Heterotroph Plate Counts (HPC) represented as (Colony Forming Units) CFU/L.

During operation of the SNS accelerator, scattering of the proton beam may subject the cooling water to direct spallation and activation. Be-7 is a radionuclide produced through the direct spallation of oxygen and is largely responsible for the activity in the cooling water. In addition, spallation neutrons activate corrosion products present in the water and in turn generate long-lived radionuclides including Co-60, Zn-65, and Mn-54 [2]. Radioactivity in the cooling system is of concern due to the potential for contamination of hardware and personnel. Safe accelerator operation demands that the quantity of activated water, caused primarily by $\mathrm{Be}-7$, be minimized. Deionization has proven to be a very effective process for the removal of Be-7 [2] from accelerator cooling water.

To obtain the desired water cooling system purity, several basic parametric ranges were adhered to. To minimize erosion, water flows in the cooling systems are kept below $2.5 \mathrm{~m} / \mathrm{s}$ on surface impingement areas such as tees and elbows, and less than $5 \mathrm{~m} / \mathrm{s}$ in straight sections. To minimize scaling, a narrow temperature band of the cooling water, 10 to $25^{\circ} \mathrm{C}$, was defined.

Other critical parameters, which have been defined and will be controlled, include electrical resistivity, pressure, $\mathrm{pH}$, and dissolved $\mathrm{O}_{2}$ content. Typically an electrical resistivity value above $6 \mathrm{M} \Omega-\mathrm{cm}$ drastically reduces scaling [3]. However, it is important to keep the resistivity below $15 \mathrm{M} \Omega$-cm, particularly in copper structures and piping. Due to the polar nature of ultrapure water, a very high resistivity tends to strip away ions from the metal surface of piping, particularly copper when dissolved oxygen is present [4]. Maintaining the resistivity below $15 \mathrm{M} \Omega$-cm minimizes this effect. Analog pressure gauges will be used to indicate system pressure and indicate filter-loading information for filter replacement. Approximately $1-5 \%$ of the main water flow will be diverted to the water purification loop, the quantity being monitored with a flow meter. The flow in this loop requires an oxygen content of less than $20 \mathrm{ppb}$ to minimize corrosion [5] and bacterial growth. When copper is exposed, the corrosion is embodied as insoluble particles of $\mathrm{CuO}$ and $\mathrm{Cu}_{2} \mathrm{O}$, which amass in the system after removal from the parent surface. Filtration is helpful in reducing this effect, however minimizing oxygen in the system proves more effective [5].

Table 1 summarizes the water quality to be obtained from the water purification system. 
Table 1. Water purification parameters.

\begin{tabular}{|c|c|c|}
\hline Parameter & Value & Reference \\
\hline $\begin{array}{c}\text { Flow rate } \\
\text { (through } \\
\text { purification tanks) }\end{array}$ & $\begin{array}{c}1-5 \% \text { of total } \\
\text { flow }\end{array}$ & {$[6]$} \\
\hline $\mathrm{pH}$ & $8+/-1$ & {$[7]$} \\
\hline $\begin{array}{c}\text { Electrical } \\
\text { Resistivity }\end{array}$ & $10-15 \mathrm{M} \Omega-\mathrm{cm}$ & {$[4],[8]$} \\
\hline $\begin{array}{c}\text { Dissolved Oxygen } \\
\text { Content }\end{array}$ & $<20 \mathrm{ppb}$ & {$[9]$} \\
\hline Particulate size & $\leq 1$ micron & \\
\hline
\end{tabular}

\section{MECHANICAL DESIGN}

The SNS Linac water-cooling purification system was designed with the intent of minimizing erosion, corrosion, scaling, biological growth, and hardware activation. Each component was selected to target the removal of a specific impurity, and in some cases, multiple impurities.

The water purification system is shown as a side flow loop in the water cooling system flow diagram of Figure 2. A 5-micron pre-filter sieves out the largest contaminants. Following the filter, the water will pass through an oxygen scavenger resin canister, similar to the system used in the APS Linac Water Cooling System [5]. The carbon canister removes hydrocarbon contaminants, including residual petroleum products remaining in the piping from manufacturing processes. The carbon canister can be valved-off when no longer needed, to prevent excessive carbon particulates from entering the cooling system. After passing through the carbon adsorption canister, the water then passes through the deionization canisters, where any free ions remaining in the system are removed. Next, an ultraviolet light source is used to kill surviving bacteria, which are then filtered out by a 1-micron filter. At this point in the system, the water is quite pure. The pure or polished water will then be returned to the main loop.

The piping material will consist of stainless steel, which serves as an effective barrier between the atmosphere and the cooling water, minimizing $\mathrm{O}_{2}$ permeation. Due to the corrosive nature of deionized water, brass and carbon steel components are not acceptable. Flexible tubing will be used as transfer lines to avoid the need for high tolerances in the water line designs and to serve as vibration isolators. Several flexible tube options were explored. Material selection was based on DI water compatibility, low oxygen permeation rates, and resistance to radiation.

Various types of instrumentation will be used to monitor and record the performance of the water purification system. Instrumentation will be provided to measure electrical resistivity, pressure, flow rate, $\mathrm{pH}$, and dissolved $\mathrm{O}_{2}$ content. Parameters that cannot be easily monitored with sensors or their capital costs make them prohibitive include particulate, bacteria, Total Organic Carbon (TOC), heterotroph plate counts (HPC) and trace elements. Particulate sampling will verify the filters are removing the desired particulate size. TOC and HPC testing will indicate bacterial and carbon based populations. Testing for trace elements such as iron, copper, and zinc, elements used in the piping system will indicate negative effects of the DI water on the piping system. A water sample should be taken after initial startup, after water has circulated through the purification loop. Samples should also be taken periodically and after major water system hardware configuration changes.

\section{SUMMARY AND FUTURE WORK}

A water purification system design, based on the water purity requirements of the SNS Linac water cooling system, was presented. The purification hardware will minimize scaling, corrosion, bacteria growth, and activation. Instrumentation was proposed to monitor $\mathrm{pH}$, electrical resistivity, and dissolved oxygen content. Water sampling will be required to assess bacterial growth, particulate accumulation, and corrosion.

A prototype SNS linac water cooling system, including water purification hardware and instrumentation, has been fabricated and is undergoing extensive testing. The results of these tests will aid in determining the adequacy of the proposed purification system design in meeting the desired operating parameters.

\section{REFERENCES}

[1] Saito, K., Sasaki, K., Seki, E., Arai, K., Negishi, K., and Higuchi, T., "Degassing Effect in Water - Sterilizing Effect," $8^{\text {th }}$ Workshop on RF Superconductivity, Padova, Italy, 1997.

[2] Degueldre, C., Bilewicz, A., and Alder, H.P., "Behavior and Removal of Radionuclides Generated in the Cooling Water of a Proton Accelerator", Nuclear Science and Engineering, Vol.120, pp. 65.

[3] Gibbs, G., CLWS Inc., Telephone conversation "Water Purity," Nov. 4, 1999.

[4] Wood, R., LANSCE-1, Personal Correspondance, "DI Water and Copper Piping," Los Alamos National Laboratory, Los Alamos, NM.

[5] White, M., Dortwegt, R., Pasky, P., "Improved Temperature Regulation and Corrosion Protection of APS Linac RF Components", 1999 Particle Accelerator Conference, New York City, NY, 1999.

[6] Richards, M.B., Luu, R.K., Paciotti, M.A., “ APT Coolant and Plateout Studies", Presentation Material, Los Alamos National Laboratory, Los Alamos, NM.

[7] Boedeker, W., Meetings on LANSCE Purification Systems 6/01/99 - 8/13/99, LANSCE-2 Group, Los Alamos National Laboratory, Los Alamos, NM.

[8] Chao, A.W., and Tigner, M., Handbook of Accelerator Physics and Engineering, World Scientific.

[9] Cartwright, P., Designing Pure Water Systems, Presentation Material, Cartwright Consulting Company, Minneapolis, MN. 